\title{
KESERAGAMAN JENIS-JENIS IKAN PADA KOMUNITAS MANGROVE DESA WAAI KECAMATAN SALAHUTU KABUPATEN MALUKU TENGAH
}

\author{
Lisca Pelupessy ${ }^{1}$, Ine Arini², \\ ${ }^{1}$ Alumi Program Studi Pendidikan Biologi \\ ${ }^{2}$ Dosen Program Studi Pendidikan Biologi \\ E-mail:
}

\begin{abstract}
Background: Fish are the basic organisms of waters living on the surface of the water or at the bottom of the water. Fish is one of the important resources that can provide benefits for recreation, economic value and science for the community. The beach is located in Waai Village is faced with Haruku Island and West Seram Island. Waai beach area found mangrove community.

Method: The study was conducted approximately 1 month. Starting from January 27, 2016 to February 27,2016 . Tipe research used is descriptive where only see uniformity and diversity of species of fish in the coastal waters of Waai Village by using the existing formula.

Result: The research results showed that fish species in coastal waters of Waai Village found 16 species with uniformity index which is moderate is 1.642 and diversity is 2,154.

Conclusion: The index of diversity and uniformity of fish species in coastal mangrove community of Mangai State belong to medium category, with index of diversity 2,514 and uniformity value 1.642 this is influenced by environmental condition.
\end{abstract}

Keywords: uniformity and diversity, Type of Fish, Waai Village.

\begin{abstract}
Abstrak
Latar Belakang: Ikan adalah organisme dasar perairan yang hidup di permukaan air atau di dasar perairan. Ikan merupakan salah satu sumber daya penting yang dapat memberikan manfaat antara lain untuk rekreasi, nilai ekonomi dan ilmu pengetahuan untuk masyarakat. Pantai yang terletak di Desa Waai ini berhadapan dengan Pulau Haruku dan Pulau Seram Bagian Barat. Kawasan pantai Waai dijumpai komunitas mangrove.

Metode: Penelitian dilaksanakan kurang lebih 1 bulan. Dimulai dari tanggal 27 Januari2016 sampai 27 Febuari 2016. Tipe penelitian yang digunakan adalah deskriptif dimana hanya melihat keseragaman dan keanekaragaman jenis Ikan pada perairan pantai Desa Waai dengan menggunakan rumus yang ada. Hasil: Hasil penelitian menujukan Bahwa jenis ikan pada perairan pantai Desa Waai di temukan 16 spesies dengan Indeks Keseragaman yang tergolong sedang yaitu 1,642 dan keanekaragaman yaitu $2,154$.

Kesimpulan: Indeks keanekaragaman dan keseragaman jenis ikan di komunitas mangrove pantai Negeri waai tergolong dalam kategori sedang,dengan indeks keanekaragaman 2.514 dan nilai keseragaman 1.642 hal ini dipengaruhi oleh kondisi lingkungan.
\end{abstract}

Kata Kunci : Keseragaman dan Keanekaragaman, Jenis Ikan, Pantai Desa Waai. 


\section{PENDAHULUAN}

Ikan adalah organisme dasar perairan yang hidup di permukaan air ataupun di dasar perairan. Secara teoritis bahwa ikan dan binatang lainnya berasal dari suatu "daerah tertentu" pada salah satu tempat di belahan bumi kita ini. Dari daerah tertentu tersebut ikan-ikan menyebar ke suluruh bagian bumi kita, baik secara aktif maupun secara pasif. Undang-Undang Rebublik Indonesia No. 16 Tahun 1992 Tentang Karantina Hewan, Ikan Dan Tumbuhan, pada pasal 1 angka 10, menyebutkan bahwa Ikan adalah semua biota perairan sebagian atau seluruh daur hidupnya berada di dalam air, dalam keadaan hidup atau mati, termasuk bagian-bagiannya.

Sejalan dengan itu, maka wilayah geografis provinsi Maluku sebagai bagian dari Negara Kesatuan Republik Indonesia memiliki luas wilayah perairan (laut) mencapai $92 \%$, sehingga sudah tentu memiliki jenis ikan yang beraneka ragam. Salah satu wilayah yang memiliki potensi keragaman ikan pada komunitas mangrove adalah wilayah pesisir pantai Waai.Komunitas mangrove didominasi oleh berbagai pepohonan yang khas serta memiliki kemampuan untuk tumbuh dan berkembang diperairan asin.

Pantai Waai terletak di ujung timur Pulau Ambon, pada bagian yang berlekuk mirip mulut ikan yang menganga. Jaraknya sekitar satu jam berkendara menyusuri pantai teluk Ambon, melalui pusat Kota Ambon, lalu menyusuri Pantai Natsepa yang populer menjadi tujuan wisatawan. Pantai yang terletak di Desa Waai ini berhadapan dengan Pulau Haruku dan Pulau Seram bagian barat. Kawasan pantai Waai dijumpai komunitas mangrove. Ekosistem hutan mangrove merupakan tipe ekosistem yang terdapat di daerah pantai yang selalu digenangi air laut atau dipengaruhi oleh pasang surut air laut dan merupakan pantai dengan kondisi tanah berlumpur, berpasir atau lumpur berpasir (Indriyanto, 2010).

Dari keseluruhan vertebrata yaitu sekitar 50.000 jenis hewan, ikan merupakan kelompok terbanyak diantaranya dan memiliki jenis atau spesies yang terbesar yaitu sekitar 25.988 jenis yang tergolong dalam 483 famili dan 57 ordo. Ikan merupakan salah satu sumberdaya penting yang dapat memberikan manfaat antara lain untuk rekreasi, nilai ekonomi dan ilmu pengetahuan untuk masyarakat.

Berdasarkan uraian di atas, maka penulis tertarik untuk melakukan tindakan penelitian secara mendalam dengan memilih judul: Keragaman Jenis-Jenis Ikan Pada Komunitas Mangrove Desa Waai Kecamatan Salahutu Kabupaten Maluku Tengah. Penelitian ini bertujuan untuk mengetahui keanekaragaman jenisikan yang terdapat di ekosistem mangrove desa Waai Kecamatan Salahutu Kabupaten Maluku Tengah. Penelitian ini diharapkan dapat memberikan manfaat berupa informasi mengenai jenis dan keanekaragaman jenis ikan di desa Waai Kecamatan Salahutu Kabupaten Maluku Tengah sehingga dapat digunakan sebagai acuan untuk pengelolaan maupun penelitian lebih lanjut.

\section{MATERI DAN METODE PENELITIAN Jenis Penelitian}

Jenis penelitian ini adalah penelitian deskritif. Penelitian ini dilakukan pada tanggal 27 Januari - 27 Pebuari 2016 berlokasi di kawasan pantai Desa Waai Kecamatan Salahutu Kabupaten Maluku Tengah. Populasi dalam penelitian ini adalah seluruh ikan yang ada pada Komunitas mangrove Desa Pantai Waai Kecamatan Salahutu Kabupaten Maluku Tengah, dengan luas daerah penelitian $150 \mathrm{~m}$ menggunakan stasiun sebanyak 3 stasiun, jarak antar Stasiun $50 \mathrm{~m}$.

\section{Sampel}

Sampel dalam penelitian ini adalah jenis jenis ikan pada komunitas manggrove, yang berada pada tiap Stasiun, dengan cara purporsive sampling.

\section{Alat dan Bahan}

Alat dan bahan yang digunakan dalam penelitian ini dapat dilihat pada tabel 3.1, sebagai berikut. 
Tabel 1. Alat dan Bahan Penelitian

\begin{tabular}{|c|c|c|}
\hline No & Alat/ Bahan & Fungsi/ Kegunaan \\
\hline 1 & Jaring tutup/ insang & Untuk menangkap ikan dengan cara ditebarkan \\
\hline 2 & Kamera 8 mega pixel (merek & Untuk mendokumentasikan \\
\hline & Sony) & berbagai kegiatan penelitian \\
\hline 3 & $\begin{array}{l}\text { Global Positioning System } \\
\text { (GPS) }\end{array}$ & Untuk menentukan koordinat/ lokasi \\
\hline 4 & Kantong Plastik & $\begin{array}{l}\text { Sebagai wadah koleksi jenis ikan untuk } \\
\text { kebutuhan penelitian }\end{array}$ \\
\hline 5 & Meter Roll & Untuk mengukur garis stasiun \\
\hline 6 & Penggaris dan alat tulis menulis & Untuk mencatat Temuan penelitian \\
\hline 7 & Formalin $5 \%$ & Untuk pengawetan \\
\hline 8 & Kertas label & $\begin{array}{l}\text { Untuk memberi label pada spesies yang } \\
\text { ditemukan pada mesing - masing stasiun }\end{array}$ \\
\hline
\end{tabular}

Data Primer, 2016

\section{Prosedur Penelitian}

\section{Tahap Persiapan}

Pada tahap ini di lakukan studi pendahuluan (observasi), untuk menentukan lokas-lokasi untuk pengambilan data. Disamping itu dilakukan persiapan alat dan bahan yang diperlukan serta pengarahan kepada 2 orang warga.

\section{Tahap Pelaksanaan}

a. penentuan lokasi pengambilan data penelitian ini dilakukan pada zona intrtidal dengan luas lokasi penelitian \pm 150 meter. Pada pantai di buat 3 Stasiun dengan jarak antar Stasiun $50 \mathrm{~m}$ secara vertikal mulai dari batas pasang tertinggi sampai surut terendah, setiap jenis ikan yang ada pada tiap Stasiun dihitung. Jenis ikan tersebut kemudian diawetkan dan selanjutnya di masukan kedalam plastik, serta di berikan label sesuai lokasi pengamatan. Apabila belum di ketahui nama jenis ikan yang di temukan akan dilaukan proses identifikasi pada Lembaga Ilmu Pengatahuan Indonesia( LIPI). Jenis- jenis ikan yang ditemukan pada setiap Stasiun kemudian diidentifikasi nama jenis ikan dan klasifikasi ikan,disesuaikan dengan buku jenis - jenis ikan.

b. Pengambilan Data

Pengambilan data dilakukan pada zona intertidal dengan metode transek garis yang disesuaikan dengan kondisi lapangan. Pembuatan transek dilakukan dengan menarik garis tegak lurus dari garis pantai sepanjang 150 meter, kemudian dibuat garis transek paralel dengan jarak antar Stasiun masingmasing 50 meter menggunakan roll meter.

Data penelitian yang diperoleh selanjutnya diolah dengan menggunakan indeks keragaman Shannon-Wienner sebagai berikut:

$H^{\prime}=-\sum(\mathbf{P i}$ 1n Pi)

Di mana:

$\mathrm{Pi}=\frac{n i}{N}$

Keterangan :

H' : Indeks keanekaragamanjenis

ni : Jumlah individu jenis ke-1

$\mathrm{N} \quad$ : Jumlah total individu semua jenis dalam komunitas

$\mathrm{Pi} \quad$ : kelimpahan relative

$\Sigma \quad$ : jumlah spesies individu

Bila :

$\mathrm{H}^{\prime}<1=$ keanekaragaman rendah

$\mathrm{H}^{\prime} \leq 1 \mathrm{H}^{\prime} \leq 3=$ keanakaragaman sedang

$\mathrm{H}^{\prime}>3=$ keanakaragaman tinggi

HASIL DAN PEMBAHASAN

Hasil Penelitian

Gambaran Umum Lokasi Penelitian

Letak dan Batas Lokasi

Desa Waai adalah salah satu desa di kecamatan Salahutu kabupaten Maluku Tengah yang berada di pesisir pantai yang berbatasan dengan sebelah selatan desa Liang dan timur dengan desa Tulehu 
Kabupaten maluku Tengah. Dengan jumlah penduduk 7.644 jiwa diantaranya laki laki 3.774 jiwa dan perempuan 3.870 jiwa. Secara administratif Negeri Waai termasuk dalam wilayah Kecamatan Salahutu, Kabupaten Maluku Tengah, dan terletak sebelah Timur Kabupaten Maluku Tengah.

Luas wilayah Negeri Waai adalah $10.439,60 \mathrm{Ha}$ terdiri dari daratan 7.615,70 $\mathrm{Ha}$ dan laut 2.823,90 $\mathrm{Ha}$, sedangkan luas kawasan pemukiman adalah 3.594,64 Ha, dengan memiliki garis pantai panjang $10 \mathrm{Km}$, dengan batas-batas sebagai berikut:

Sebelah Utara: Petuanan Negeri Liang, Kecamatan Salahutu

Sebelah Selatan: Petuanan Negeri Tulehu, Kecamatan Salahutu

Sebelah Barat: Petuanan Negeri MamalaMorela Kecamatan Leihitu

Sebelah Timur: Selat Haruku/Laut

\section{Topografi dan Jenis Tanah}

Kondisi topografi sebagian besar petuanan Negeri Waai khusus pada daerah sebelah barat adalah berlereng dan berbukit dengan kemiringan rata-rata di

atas $15^{\circ}$, sedangkan pada daerah pemukiman relatif datar dan linier sepanjang pantai yang membujur dari arah Selatan ke Utara. Jenis tanah sangat didominanoleh tanah berpasir, merah kuning.

\section{Jenis-jenis Ikan Yang Terdapat di Daerah perairan pantai Desa Waai Kecamatan Salahutu Kabupaten Maluku Tengah}

Berdasarkan hasil identifikasi tentang keanekaragaman jenis ikan yang terdapat diperairan pantai Desa Waai Kecamatan Salahutu kabupaten Maluku Tengah dapat di ketahui bahwa jenis ikan hidup tersebar pada subsrat yang ada pada komunitas manggroveyang ada pada lokasi penelitian.Jenis -jenis ikan yang terdapat pada lokasi penelitiandapat di lihat pada Tabel 4.1 berikut.

Tabel 2. Jumlah Jenis Ikan yang Terdapat pada Daerah Penelitian

\begin{tabular}{clc}
\hline No & \multicolumn{1}{c}{ Nama Spesies } & Jumlah individu \\
\hline 1 & Mugil cephalus (lkan Bulana) & 14 \\
2 & Caranx sexfasciatus( ikan Bubara) & 49 \\
3 & Upeneus tragula,(Ikan biji nangaka/ Samaneti) & 15 \\
4 & Diodon liturosus( Ikan durian) & 6 \\
5 & Lutjanus fulviflama ( Ikan Sikuda) & 25 \\
6 & Chaetodon lunula (lkan Daun) & 22 \\
7 & Lethrinus harak(lkan Sikuda) & 16 \\
8 & Chelonodon patoca (Ikan Buntal) & 8 \\
9 & Rhinecanthusverucosus (Ikan tatu kuning) & 14 \\
10 & Gerres Macrosoma( Ikan Perak) & 30 \\
11 & Gerres oyena (Ikan Perak) & 18 \\
12 & Upeneus vittatus (Ikan Jenggot) & 7 \\
13 & Siganus canaliculatus ( Ikan samandar) & 31 \\
14 & Siganus lineatus (ikan samandar) & 13 \\
15 & Taeniura lymma (Ikan Pari) & 2 \\
16 & Tylosurus gavialoides (lkan Saku) & 5 \\
\hline \multicolumn{4}{c}{ Jumlah } & $\mathbf{2 7 7}$ \\
\hline
\end{tabular}

Berdasarkan Tabel 2 pada daerah penelitian yang terletak pada perairan pantai desa Waai, secara keseluruhan pada daerah penelitian ini di temukan 16 spesies yang tergolong dalam 12 family, atau dapat di lihat pada Tabel 4.2. lampiran 4

\section{Indeks Keanakaragaman ( $\left.\mathrm{H}^{\prime}\right)$}

Berdasarkan data dapat diketahui bahwa indeks keanekaragaman jenis ikan pada perairan pantai desa Waai Kecamatan Salahutu Kabupaten Maluku Tengah mempunyai nilai yang berbeda beda. Pada daerah penelitian indeks keanekaragaman ikan yang tertinggi yaitu 0.243 dan indeks keanekaragaman terendah yaitu 0.018 . 
Rata- rata indeks keanekaragaman jenis ikan pada daerah penelitian yaitu 2.154.

\section{Indeks Keseragaman (E ')}

Berdasarkan tabel 4.4 pada lampiran 6 dapat diketahui indeks Keseragaman jenis ikan pada perairan pantai Desa Waai kecamatan Salahutu Kabupaten Maluku Tengah mempunyai nilai yang berbedabeda. Pada lokasi penelitian Indeks keseragaman jenis yang tertinggi yaitu pada spesies Taeniura lymma dengan nilai 0.499 dan nilai keseragaman jenis terendah yaitu pada spesiesUpeneus tragula dengan nilai 0.008. Jumlah total nilai indeks keseragaman jenis ikan pada lokasi penelitian yaitu 1.642 .

Deskripsi Jenis ikan yang di temukan pada Daerah Perairan Pantai Desa Waai Kecamatan Salahutu Kabupaten Maluku Tengah.

\section{Mugil cephalus}

Jenis ikan Bulana (Mugil cephalus) memiliki tubuh yang panjang $33 \mathrm{~cm}$ dan hampir berbentuk silinder.

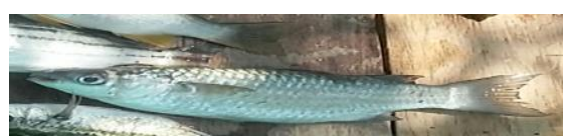

\section{Gambar 1. Ikan Mugil cephalus}

\section{Caranx sexfasciatus}

Berdasarkan hasil penelitian Tubuh ikan Caranx Sexfasciatus berbentuk oval dan pipih Warna tubuhnya bervariasi,yaitukuning bagian atas dan perak hingga keputihputihan dibagian bawah.

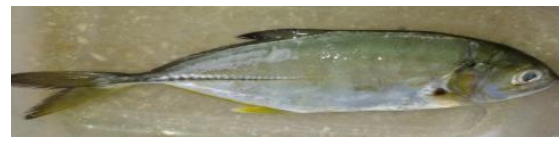

\section{Gambar 2 Ikan Caranxsexfasciatus}

\section{Upeneus tragula}

Berdasarkan hasil penelitian, panjang ikan upenus tragula $20,1 \mathrm{~cm}$, bentuk tubuh ikan ini memanjang dan bersisik halus, warna dasar tubuhnya berbintik - bintik coklat keemasaan.

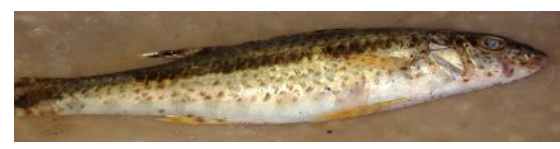

\section{Gambar 3 Ikan Upeneus tragula}

4. Diodon liturosus

Ikan Diodon liturosus berkarabat dengan ikan buntal. Tubuhnya lebar serta buntak dan tertutup oleh lempeng-lempeng tulang kecil. Mulutnya terletak di ujung dan kecil.

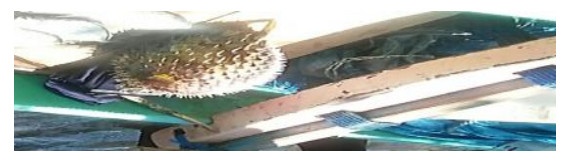

\section{Gambar 4 Diodon liturosus}

\section{Lutjanus fulviflamma}

Ikan Lutjanus fulviflamma 21,2 cm. tubuhnya memanjang bersisik halus, warna tubuhnya putih keemsan, memiliki garisgaris tegak dan pada sirip punngunggya terdapat garis- garis miring, dengan nama lokalnya sikuda dan nama inggrisnya black Spot Seaperch.

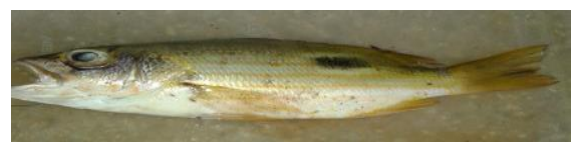

\section{Gambar 5. Lutjanus fulviflamma}

\section{Chaetodon Iunula}

Ikan chaetodon lunula berbentuk daun dan berangsur mengecil ke arah mulut, dan sebuah misai kecil meningkatkan penyamaran dengan mayerupai tangkai daun.

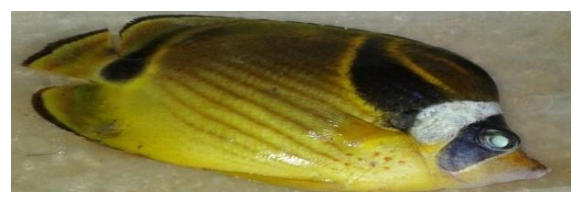

\section{Gambar 6 Ikan Chaetodon Iunula}

\section{Lethrinus harak}

Warna tubuh ikan Lethrinus harak putih kecokelatan dan memiliki panjang $20,3 \mathrm{~cm}$, serta memiliki siripdan sisik yang tebal,nama lokalnya adalah Sikuda dan nama inggrisnya adalah Thumbprint Emperor. 


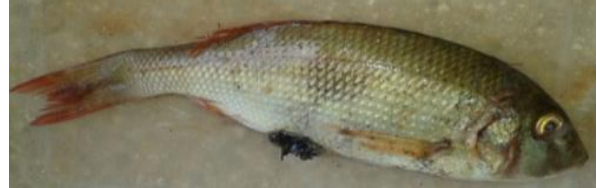

Gambar 7 Ikan Lethrinus harak

\section{Chelonodon patoca}

Ikan Chelonodon patoca memiliki bentuk badan memanjang dengan kepala gepeng dan lebar, warna badan kecoklatan dan atau hitam.

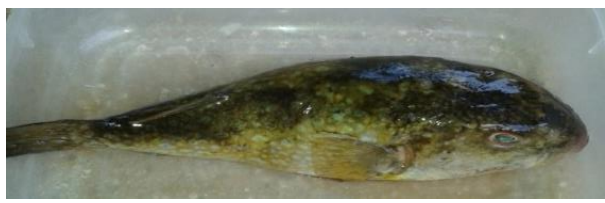

\section{Gambar 8 lkan Chelonodon patoca}

\section{Rhinecanthus verrucosus}

Panjang ikan Rhinecanthus verrucocus adalah $21,3 \mathrm{~cm}$. warna tubuh bagian atas ikan ini putih kekuning -kuningan dan pada bagian bawah berwarna hitam kecoklatan.

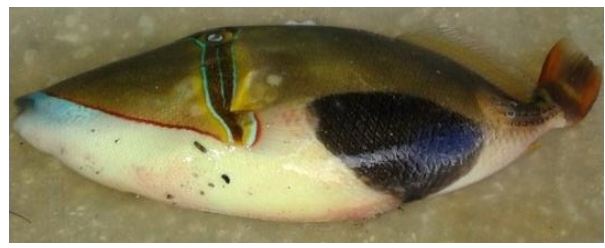

\section{Gambar 9 Ikan Rhinecanthus verrucocus}

\section{Gerres macrosoma}

Ikan Gerres macrosoma memiliki bentuk tubuh pipih, mulut tegak runcing ke depan, jari-jari kedua sirip punggung memanjang seperti rambut. Tubuh di tutupi oleh sisik berukuran besar, warna tubuh keperakan.

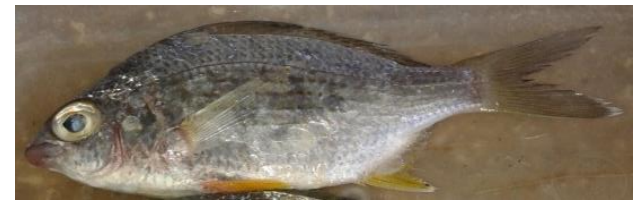

\section{Gambar 10 lkan Gerres macrosoma}

\section{Gerres oyena}

Berdasarkan hasil penlitian panjang ikan Gerres Oyena 19,1 cm. Badan pada umumnya berwarna keperak - perakan serta memiliki sirip dan sisiknya yang halus.nama lokalnya dalah ikan perak dan nama inggrisnya adalah common silver Biddy.

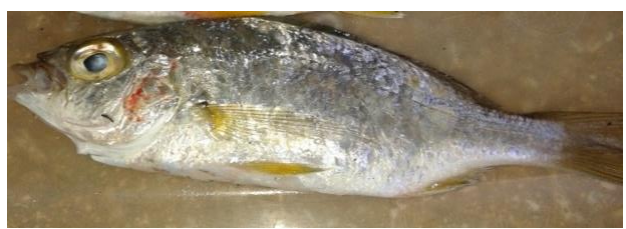

\section{Gambar 11 ikan Gerres oyena}

12. Upeneus vittatus

Berdasarkan hasil pnelitian ikan Upeneus vittatus memiliki panjang $22,4 \mathrm{~cm}$ serta memiliki sirip dan warna tubuh putih bergaris coklat keemasan. Yang mempunyai nama lokal adalah Ikan Jenggot dan nama inggrisnya adalah Stripet goad fish.

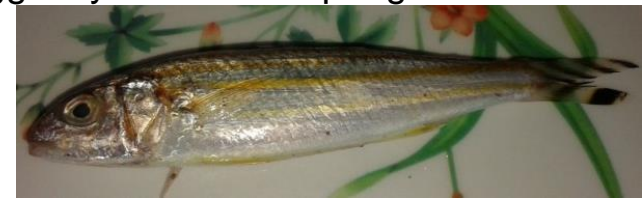

\section{Gambar 12 Ikan Upeneus vittatus}

\section{Siganus canaliculatus}

Berdasarkan hasil penelitian warna tubuh ikan Siganus canaliculatus putih berbintik- bintik kuning, suatu spesies yang panjangnya $21,5 \mathrm{~cm}$.

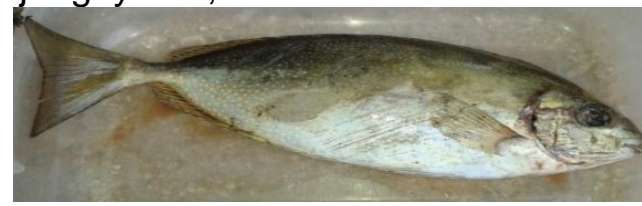

\section{Gambar 13 Ikan Siganus canaliculatus}

\section{Siganus lineatus}

Berdasarkan hasil penlitian warna tubuh ikanSiganus lineatus hitam berbintik-bintik coklat, bertubuh lebar dan memiliki sirip, ikan ini sangat digemari oleh para penggemar karena nilai ekonomisnya.ikan ini memiliki panjang $23,5 \mathrm{~cm}$.

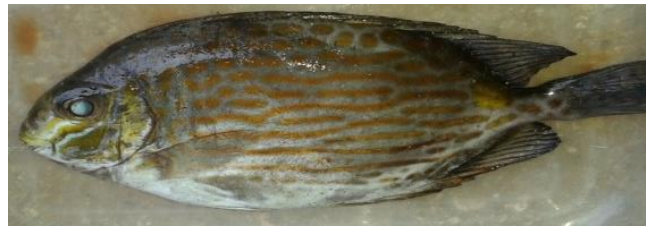

Gambar 14 Ikan Siganus lineatus 


\section{Taeniura limma}

Berdasarkan hasil penelitian ikan termasuk ikan bertulang rawan. Bentuk tubuhnya pipih mendatar. Warna dasar punggungnya kecoklatan, di seluruh tubuhnya menyebar bulatan biru cerah.

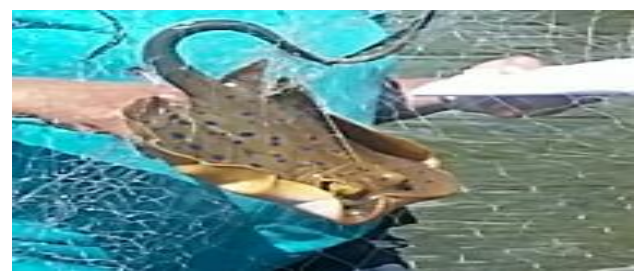

\section{Gambar 15 Ikan Taeniura limma}

\section{Tylosurus gavialoides}

Ikan Tylosurus gavialodies, suatu kelompok ikan air laut bertubuh memanjang dengan nama lokalnya ikan balobo, nama inggris Stout Longtom. Panjangya 67,5 cm.

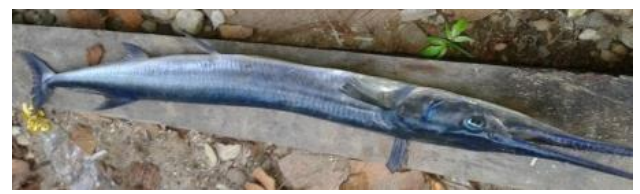

\section{Gambar 16 Ikan Tylosurus gavialoides}

\section{Pembahasan}

Berdasarkan hasil penelitian diketahui terdapat 16 jenis ikan yang hidup di komunitas mangrove pantai Negeri Waai yakni Mugil cephalus (Ikan Bulana), Caranx sexfasciatus (Bubara), Upeneus tragula, (Ikan biji nangak/Samaneti), Tetraodontidae (Durian), Lutjanus fulviflama (Ikan Sikuda), Chaetodon lunula (Ikan Daun), Lethrinus harak (Ikan Sikuda), Chelonodon patoca (lkan Buntal), Rhinecanthusverucosus (Ikan tatu kuning), Gerres Macrosoma (Ikan Perak), Gerres oyena (Ikan Perak), Upeneus vittatus (Ikan Jenggot), Siganus canaliculatus (Ikan samandar), Siganus lineatus (ikan samandar), Taeniura lymma (Ikan Pari), Tylosurus gavialoides (Ikan Saku), perbedaan jumlah jenis ikan pada ketiga stasiun kemungkinan dipengaruhi oleh kondisi dan struktur komunitas mangrove di pantai Negeri Waai.

Cara penankapan ikan pada komunitas mangrove dipanatai Desa Waai menggunakan jaring dengan panjang $150 \mathrm{~m}$ dan lebar $70 \mathrm{~m}$
Selain identifikasi jenis ikan, dihitung pula indeks keanekaragaman jenis ikan pada komunitas mangrove tersebut. Hasil penelitian yang di peroleh yaitu indeks keanekaragaman jenis ikan pada lokasi penelitian secara rata-rata adalah kurang dari 3, dengan demikian indeks keanekaragaman jenis ikan di komunitas mangrove Negeri Waai tergolong sedang.

Indeks keanekaragaman ShannonWiener selain dapat menggambarkan keanekaragaman jenis, juga dapat menggambarkan produktivitas ekosistem, tekanan pada ekosistem, dan kestabilan ekosistem. Semakin tinggi nilai indeks $\mathrm{H}^{\prime}$ maka semakin tinggi pula keanekaragaman jenis, produktivitas ekosistem, tekanan pada ekosistem, dan kestabilan ekosistem demikian pula sebaiknya. Indeks $\mathrm{H}^{\prime}$ jenis ikan pada komunitas mangrove di pantai Negeri Waai yang sedang menunjukkan adanya tekanan ekologis yang berat dan ekosistem tidak stabil. Hal itu dipengaruhi oleh aktivitas masyarakat yang berada di sekitar pantai Negeri Waai. Aktivitas tersebut adalah penangkapan ikan oleh masyarakat mulai dari tahap juwenil, juwana dan dewasa. Jika di bandingkan dengan hasil penelitian yang diperoleh dimana indeks keseragaman jenis ikan pada lokasi penelitian secara rata- rata adalah lebih dari 1. Dengan demikian keseragaman jenis ikan pada komunitas mangrove di pantai Desa Waai adalah memiliki keseragaman yang minimum.

Angka indeks keseragaman jenis ikan pada komunitas mangrove di pantai Negeri Waai tergolong dalam kategori sedang. Semakin kecil nilai E (indeks keseragaman), maka semakin kecil pula keseragaman populasi. Apabila penyebaran jumlah individu setiap jenis tidak sama dan ada kecenderungan satu spesies mendominasi.

Adapun kondisi komunitas mangrove di pantai Negeri Waai masih alami namun keanekaragaman dan keseragaman jenis ikan pada komunitas mangrove tersebut tergolong dalam kategori rendah. Penyebab indeks keanekaragaman dan keseragaman tergolong rendah karena dipengaruhi oleh lingkungan pantai Negeri waai, karena kondisi perairan dan lingkungan fisik sangat berperan dalam distribusi ikan dan metabolisme ikan. Sesuai pendapat Effendi (2003) faktor-faktor yang berpengaruh 
terhadap kelimpahan ikan diperairan diantaranya adalah suhu, salinitas, kelarutan oksigen, dan kandungan bahan organik.

Seluruh jenis ikan yang tertangkap di lokasi penelitian relative berukuran juvenile ( $85-95 \%$ ). Hasil ikan yang ditangkap perolehannya belum dapat dikatakan dewasa, hanya berukuran remaja. Hal tersebut sejalan dengan pendapat Odum (1971), yang menyatakan ekosistem Mangrove dikenal sebagai daerah asuhan. Hal ini juga menujukan bahwa fungsi Biologi kawasan Mangrove sebagai kawasan pemijah (spawning graund) atau asuhan (nursery graund) bagi Udang, ikan, kepiting dan sebagainya yang setelah dewasa akan kembali ke lepas pantai ( Saparinto, 2007).

\section{KESIMPULAN DAN SARAN Kesimpulan}

Berdasarkan hasil penelitian, maka kesimpulan yang dapat diambil adalah sebagaiberikut:

1. Jumlah jenis- jenis ikan yang terdapat pada komunitas mangrove desa Waai Kecamatan Salahutu Kabupaten Maluku Tengah pada areal penelitian yaitu 16 Spesies yang tergolong dalam 12 Family.

2. Indeks keanekaragaman dan keseragaman jenis ikan di komunitas mangrove pantai Negeri waai tergolong dalam kategori sedang,dengan indeks keanekaragaman 2.514 dan nilai keseragaman 1.642 hal ini dipengaruhi oleh kondisi lingkungan.

\section{Saran}

Dari hasil penelitian yang telah di lakukan maka ada beberapa saran yang di berikan adalah sebagai berikut:

1. Pemerintah Desa Waai untuk memperhatiakan masyarakat agar tidak membuang sampah organik maupun anorganik di pantai sehingga laut tetap terjaga kelestariannya.

2. Perlu dilakukan penelitian lanjutan dengan menggunakan metode yang lain. yang di lakukan secara keseluruhan tentang keanekaragaman jenis ikan pada komunitas Manggrove serta keterkaitannya dengan karateristik lingkungan perairan pantai.

\section{DAFTAR PUSTAKA}

Ghufran, Muhammad, 2012. Ekosistem Mangrove Potensi, Fungsi, dan Pengelolaan. Jakarta : PT. Rineka cipta Odum, E.P.1993. Dasar-dasar Ekologi. Yogyakarta: Universitas Gajah Mada Press

Saparinto, C. 2007. Pendayagunaan Ekosistem Mangrove, cetakan pertama. Dahara Prize Semarang.

Effendi, H. 2003. Telaah Kualitas Air Bagi Pengelola Sumberdaya dan Lingkungan Perairan. Kanisius : Yogyakarta.

Indriyanto. 2010. Ekologi Hutan. Bumi Aksara: Jakarta. 